\title{
Use of a ring retractor to facilitate specimen removal in laparoscopic surgery
}

Deok Ho Hong, MD¹, Miseon Kim, MD², Kidong Kim, MD, PhD, Dong Hoon Suh, MD', Jae Hong No, MD', Yong Beom Kim, MD'

Department of Obstetrics and Gynecology, 'Seoul National University Bundang Hospital, Seongnam, ${ }^{2} \mathrm{CHA}$ Gangnam Medical Center, CHA University, Seoul, Korea

\section{Objective}

To introduce a new surgical technique for specimen removal during laparoscopic surgery.

Methods

The surgical technique was described, pictured, and recorded. The surgery was performed in a tertiary hospital.

Results

During laparoscopic surgery, the specimen is resected from the surrounding tissues and contained in a specimen bag to prevent spillage. The edges of the bag are then pulled through the trocar site, and the specimen - protected by the bag-is removed. To facilitate the removal process and to prevent spillage, assistants will normally hold the edges of the bag during the process. To mitigate the need for assistants to hold the edges of the bag, we wrapped the pulled edges of the bag around a ring retractor, which is a plastic ring, to straighten the bag. This technique enabled the operator to remove the specimen without needing an assistant.

\section{Conclusion}

The technique we describe here, using a ring retractor for specimen removal, is useful when assistants are unavailable to help during laparoscopic surgery.

Keywords: Laparoscopy; Specimen handling; Operative surgical procedure; Endoscopy

Laparoscopic surgery for benign gynecologic diseases consists of trocar insertion, tissue excision/repair, and specimen extraction. Specimen extraction can be challenging if the specimens are large or solid. For example, in a study of laparoscopic myomectomy, the mean specimen extraction time was 28 minutes, despite the use of a power morcellator [1]. During specimen extraction, the use of a specimen bag is recommended to prevent spillage.

Solo surgery is defined as an operation performed by the surgeon alone, without assistants. Lack of experienced assistants and advances in technology have promoted the adoption of solo surgery, and reports of its use in various fields have shown it to be feasible [2-5]. For example, in a study that included 25 solo surgeries for hernia repair, none of the procedures required an assistant [6]. In addition, in solo laparoscopic surgeries for benign gynecologic diseases, the tissue excision/repair step can be performed using a robotic uterine manipulator and a robotic laparoscope holder [5].

However, without assistants, a key issue is whether specimen extraction is possible. When we extract specimens, assistants pull the specimen bag and facilitate the extraction by straightening the bag; this helps in preventing spillage. If

Received: 2020.01.16. Revised: 2020.03.17. Accepted: 2020.03.30. Corresponding author: Kidong Kim, MD, PhD

Department of Obstetrics and Gynecology, Seoul National University Bundang Hospital, 82 Gumi-ro 173-beon-gil, Bundanggu, Seongnam 13620, Korea

E-mail: kidong.kim.md@gmail.com

https://orcid.org/0000-0001-9254-6024

Articles published in Obstet Gynecol Sci are open-access, distributed under the terms of the Creative Commons Attribution Non-Commercial License (http://creativecommons. org/licenses/by-nc/3.0/) which permits unrestricted non-commercial use, distribution, and reproduction in any medium, provided the original work is properly cited.

Copyright $\odot 2020$ Korean Society of Obstetrics and Gynecology 


\section{Obstetrics \& Gynecology Science}

Deok Ho Hong, et al. Specimen removal using a ring retractor

we can extract specimens without assistants, then the surgery can be performed completely solo from start to finish. In addition, we can reduce injuries associated with specimen extraction. For example, knife morcellation may injure assistants who are holding the specimen bag.

Herein, we report a technique that enables specimen extraction without the need for assistants. After the specimen is placed in the specimen bag, the edges of the bag are pulled through the trocar wound. The pulled edges of the bag are wrapped around a ring retractor, which is a plastic ring, to straighten the bag. By repeatedly turning the retractor inside out, the bag is straightened by the friction between the bag and retractor. Once the bag is straightened, the operator can extract the specimen alone. When the bag is loosened, the operator can additionally turn the retractor to re-straighten the bag.

By adopting this technique, specimens can be extracted alone, without assistants. One practical tip is to use a bag one size larger than one would normally use because extra length is required for wrapping around the retractor.

\section{Acknowledgements}

We would like to thank Editage (www.editage.co.kr) for English language editing.

\section{Conflict of interest}

No potential conflict of interest relevant to this article was reported.

\section{Ethical approval}

This study was approved by the Institutional Review Board (IRB) of Seoul National University Bundang Hospital (IRB No. B-1906-547-303).

\section{Patient consent}

The need for informed consent was waived.

\section{Video clip}

Video can be found with this article online at https://doi. org/10.5468/ogs.20025.

\section{References}

1. Amemiya K, Adachi K, Sasamoto N, Yamamoto Y. Transumbilical extraction of 151-300-g myomas without morcellator versus conventional laparoscopic myomectomy with power morcellator. Gynecol Minim Invasive Ther 2017;6:162-6.

2. Lee $B$, Suh SW, Choi Y, Han HS, Yoon YS, Cho JY, et al. Solo single incision laparoscopic cholecystectomy using the parallel method; Surgical technique reducing a steep learning curve. Ann Hepatobiliary Pancreat Surg 2019;23:344-52.

3. Kang SH, Lee Y, Park YS, Ahn SH, Park DJ, Kim HH. Solo single-incision laparoscopic resectional Roux-en-Y gastric bypass for morbid obesity with metabolic syndrome. Obes Surg 2017;27:3314-9.

4. Choi BJ, Jeong WJ, Kim SJ, Lee SC. Solo-surgeon singleport laparoscopic anterior resection for sigmoid colon cancer: comparative study. J Laparoendosc Adv Surg Tech A 2018;28:330-6.

5. Maheshwari $\mathrm{M}$, Ind T. Concurrent use of a robotic uterine manipulator and a robotic laparoscope holder to achieve assistant-less solo laparoscopy: the double ViKY. J Robot Surg 2015;9:211-3.

6. Takahashi M, Takahashi M, Nishinari N, Matsuya H, Tosha T, Minagawa $Y$, et al. Clinical evaluation of complete solo surgery with the "ViKY" ${ }^{\circledR}$ " robotic laparoscope manipulator. Surg Endosc 2017;31:981-6. 